\title{
$\lg G$ and $\lg A$ autoantibodies against L1 ORF1p expressed in granulocytes correlate with granulocyte consumption and disease activity in pediatric systemic lupus erythematosus
}

Kennedy C. Ukadike ${ }^{1}$, Kathryn Ni ${ }^{1}$, Xiaoxing Wang ${ }^{1}$, Martin S. Taylor ${ }^{2}$, John LaCava ${ }^{3,4}$, Lauren M. Pachman ${ }^{5}$, Mary Eckert ${ }^{6}$, Anne Stevens ${ }^{1,7,8}$, Christian Lood $^{1+}$ and Tomas Mustelin ${ }^{1 *+}$ (1)

\begin{abstract}
Background: Most patients with systemic lupus erythematosus (SLE) have IgG autoantibodies against the RNAbinding p40 (ORF1p) protein encoded by the L1 retroelement. This study tested if these autoantibodies are also present in children with pediatric SLE (pSLE) and if the p40 protein itself could be detected in immune cells.

Methods: Autoantibodies in the plasma of pSLE patients $(n=30)$, healthy children $(n=37)$, and disease controls juvenile idiopathic arthritis (JIA) ( $n=32)$ and juvenile dermatomyositis (JDM) $(n=60)$, were measured by ELISA. Expression of p40 in immune cells was assessed by flow cytometry. Markers of neutrophil activation and death were quantitated by ELISA.

Results: IgG and IgA autoantibodies reactive with p40 were detected in the pSLE patients, but were low in healthy controls and in JIA or JDM. pSLE patients with active disease (13 of them newly diagnosed) had higher titers than the same patients after effective therapy ( $p=0.0003)$. IgG titers correlated with SLEDAI $(r=0.65, p=0.0001)$, ESR $(r=0.43, p=$ $0.02)$, and anti-dsDNA antibodies $(r=0.49, p<0.03)$, and inversely with complement C3 $(r=-0.55, p=0.002)$ and C4 $(r=$ $-0.51, p=0.006)$. p40 protein was detected in a subpopulation of CD66 $b^{+}$granulocytes in pSLE, as well as in adult SLE patients. Myeloperoxidase and neutrophil elastase complexed with DNA and the neutrophil-derived S100A8/A9 were elevated in plasma from pSLE patients with active disease and correlated with anti-p40 autoantibodies and disease activity.
\end{abstract}

Conclusions: Children with active SLE have elevated IgG and IgA autoantibodies against L1 p40, and this protein can be detected in circulating granulocytes in both pediatric and adult SLE patients. P40 expression and autoantibody levels correlate with disease activity. Markers of neutrophil activation and death also correlate with these autoantibodies and with disease activity, suggesting that neutrophils express L1 and are a source of p40.

Keywords: Pediatric lupus erythematosus, Long interspersed nuclear element, Retrotransposon, Autoantibodies, Neutrophils

\footnotetext{
*Correspondence: tomas2@uw.edu

${ }^{\dagger}$ Christian Lood and Tomas Mustelin contributed equally to this work.

'Division of Rheumatology, University of Washington, 750 Republican Street, Room E507, Seattle, WA 98109, USA

Full list of author information is available at the end of the article
}

\section{$\triangle B M C$}

(c) The Author(s). 2021 Open Access This article is licensed under a Creative Commons Attribution 4.0 International License, which permits use, sharing, adaptation, distribution and reproduction in any medium or format, as long as you give appropriate credit to the original author(s) and the source, provide a link to the Creative Commons licence, and indicate if changes were made. The images or other third party material in this article are included in the article's Creative Commons licence, unless indicated otherwise in a credit line to the material. If material is not included in the article's Creative Commons licence and your intended use is not permitted by statutory regulation or exceeds the permitted use, you will need to obtain permission directly from the copyright holder. To view a copy of this licence, visit http://creativecommons.org/licenses/by/4.0/ The Creative Commons Public Domain Dedication waiver (http://creativecommons.org/publicdomain/zero/1.0/) applies to the data made available in this article, unless otherwise stated in a credit line to the data. 


\section{Background}

Type I interferons (IFNs) play a central role in antiviral immunity [1]. They are also increased in a number of diseases, such as systemic lupus erythematosus (SLE) [2-5], dermatomyositis [6], and Sjögren's syndrome [7], which are characterized by autoimmunity against nucleic acids and proteins that associate with them. The cellular sources of these pathogenic nucleic acids and how they provoke autoimmunity are still incompletely understood [8].

A number of DNA and RNA sensors have been discovered in recent years $[9,10]$. They are widely expressed (i.e., also outside of the immune system) and they play key roles in the cell-intrinsic defense against viral infection, where they detect non-self (e.g., viral) DNA or RNA and relay this information to the innate and adaptive immune systems through the production of predominantly IFN $\beta$ (and less IFN $\alpha$ ) and upregulating $\mathrm{MHC}$ and other immune recognition molecules. It is now becoming evident that these sensors can be aberrantly activated also in autoimmune or genetic disorders that are characterized by high type I IFNs [11, 12]. Elevated cyclic guanosine adenosine phosphate [13], indicative of activated DNA sensor cGAS, and oligomerized MAVS [14], a consequence of activation of the RNA sensors MDA5 or RIG-I, are detectable in a subset of SLE patients. The nature of the DNA and RNA species that are responsible for triggering these sensors remains unclear [8].

One possible source of cytosolic DNA is the reverse transcriptase encoded by the second open-reading frame (ORF2p) of the long interspersed nuclear element (LINE-1; L1), sequences of which constitute $17 \%$ of our genome [15-18] and which are detectably expressed in patients with SLE or Sjögren's syndrome [19, 20]. ORF2p is a reverse transcriptase $[21,22]$ that, in addition to its own mRNA, can use many cellular RNAs including Alu transcripts as templates $[17,18]$ to generate RNA:DNA hybrids and double-stranded DNA that trigger IFN $\beta$ production through cGAS activation [23].

We recently reported [24] that adult SLE patients have IgG autoantibodies against the protein encoded by the first open-reading frame of L1, the RNA-binding 40-kDa ORF1p (p40). The anti-p40 autoantibodies correlated with disease activity and serological measures of the disease. Here, we extend these findings to pediatric SLE patients, asking whether retroelement activation is an early event in development of autoimmunity. With considerably lower baseline anti-p40 IgG in healthy children than seen in healthy adults, we find that the correlations between anti-p40 IgG autoantibodies and disease measures are more striking than in adult SLE patients. Pediatric lupus patients, but not adult SLE patients, also had IgA autoantibodies in circulation against p40. Furthermore, a subset of p40-expressing granulocytes were present in pediatric as well as adult SLE patients. The percentage of granulocytes expressing p40 correlated with disease activity. We also find that pSLE patients have elevated markers of neutrophil death, which also correlated closely with anti-p40 antibodies. Taken together, our data support the novel finding that L1 retroelement expression in neutrophils is an early event in SLE.

\section{Patients and methods}

pSLE patients, JIA patients, and healthy controls

A cohort of pSLE patients $(n=30)$ were recruited at Seattle Children's Hospital, from whom two plasma samples were collected, one during a period of active disease and another when the disease was inactive (SLEDAI $\leq$ 4), with a range of 1-67 (average 15.5) months between the two samples. In 13 cases, the first sample was taken at the time of diagnosis. The clinical characteristics of this cohort are summarized in Table 1. Exclusion criteria included severe anemia and inability to consent. A cohort of JIA patients $(n=32)$ and healthy age-matched individuals $(n=17)$ were also included (Table 1). An additional exclusion criterion for healthy subjects was any history of immune-mediated disorder. The study was approved by the Seattle Children's Research Hospital Human Subjects Committee. Informed written consent was obtained from the parents or guardians of all participants according to the Declaration of Helsinki.

\section{Juvenile dermatomyositis (JDM) patients and healthy controls}

A cohort of JDM patients $(n=60)$ and healthy controls ( $n=20)$ were recruited at Ann \& Robert H. Lurie Children's Hospital of Chicago, Northwestern University Feinberg School of Medicine, Chicago, IL, Institutional Review Board of which approved the study. Informed written consent was obtained from the parents or guardians of all participants according to the Declaration of Helsinki. The healthy controls from this hospital were combined with the ones from Seattle Children's Hospital giving a total of $n=37$ control samples for the ELISAs.

\section{Adult SLE patients}

A cohort of adult patients with $\operatorname{SLE}(n=10)$ were recruited through the University of Washington, Division of Rheumatology Biorepository. The study was approved by the University of Washington Institutional Review Board. Informed written consent was obtained from all participants according to the Declaration of Helsinki.

\section{ELISAs}

As described before [24], $3.3 \mu \mathrm{g} / \mathrm{ml}$ of purified p40 protein was adsorbed onto 96-well polystyrene plates in 0.1 $\mathrm{M}$ bicarbonate ( $\mathrm{pH}$ 9.6) buffer overnight, washed in 
Table 1 pSLE patients, JIA patients, and healthy controls

\begin{tabular}{|c|c|c|}
\hline Characteristic & Active pSLE $(n=30) \pm$ SD & Inactive pSLE $(n=30) \pm$ SD \\
\hline Age & $14.7 \pm 2.9$ & $14.9 \pm 2.6$ \\
\hline \multicolumn{3}{|l|}{ Laboratory measures: } \\
\hline C3 & $77.3 \pm 34.1$ & $99.9 \pm 20.0$ \\
\hline $\mathrm{C} 4$ & $9.1 \pm 7.8$ & $16.2 \pm 8.1$ \\
\hline ESR & $39.1 \pm 33.6$ & $16.1 \pm 14.2$ \\
\hline ANA & 29 & 29 \\
\hline Anti-dsDNA pos. & 20 & 15 \\
\hline \multicolumn{3}{|c|}{ Disease activity and ACR criteria: } \\
\hline SLEDAI & $10.6 \pm 4.8$ & $2.4 \pm 1.8$ \\
\hline SLEDAI $=0$ & 1 & 9 \\
\hline Arthritis & 23 & \\
\hline Oral ulcers & 13 & \\
\hline \multicolumn{3}{|l|}{ Rash } \\
\hline Nephritis & 12 & \\
\hline Pleuritis/pericarditis & 9 & \\
\hline CNS symptoms & 1 & \\
\hline Photosensitivity & 7 & \\
\hline \multicolumn{3}{|l|}{ Current treatment: } \\
\hline None & 10 & 3 \\
\hline Hydroxychloroquine & 16 & 24 \\
\hline Steroid & 16 & 22 \\
\hline Other DMARD & 13 & 19 \\
\hline Biologic only & 1 & 1 \\
\hline Characteristic & $\mathrm{JIA}(n=32) \pm \mathrm{SD}$ & Healthy children $(n=37) \pm$ SD \\
\hline Age & $13.9 \pm 2.2$ & $12.3 \pm 4.4$ \\
\hline \multicolumn{3}{|l|}{ JIA subtype: } \\
\hline Persistent oligoarticular & 7 & \\
\hline Extended oligoarticular & 6 & \\
\hline Polyarticular RF- & 17 & \\
\hline Polyarticular RF+ & 2 & \\
\hline Active disease & 24 & na \\
\hline Active joints & $3.3 \pm 3.6$ & na \\
\hline \multicolumn{3}{|l|}{ Laboratory measures: } \\
\hline RF positive & 2 & nd \\
\hline ACPA positive & 2 & nd \\
\hline ESR & $11.2 \pm 9.5$ & nd \\
\hline CRP & $0.9 \pm 0.9$ & nd \\
\hline \multicolumn{3}{|l|}{ Current treatment: } \\
\hline None or NSAID only & 7 & na \\
\hline Methotrexate only & 8 & na \\
\hline Other DMARD only & 3 & na \\
\hline Biologic only & 6 & na \\
\hline DMARD + biologic & 8 & na \\
\hline
\end{tabular}


phosphate-buffered saline with $0.05 \%$ Tween, and blocked in $2 \%$ bovine serum albumin (BSA) in phosphate-buffered saline for $2 \mathrm{~h}$. Plasma was added at $0.5 \%$ in blocking buffer (with BSA) for overnight incubation at $4{ }^{\circ} \mathrm{C}$, washed extensively, and then incubated with 1:2000 dilution of horseradish peroxidase-conjugated anti-human IgG. The reaction was then washed and developed with $\mathrm{TMB}$, with the color reaction terminated with $2 \mathrm{~N}$ sulfuric acid, and the absorbance measured at $450 \mathrm{~nm}$ using a plate reader. Autoantibodies against p40 of IgM, IgA, and IgE class were measured using the same protocol, but with secondary antibodies specific for human IgM, IgA, or IgE.

\section{Neutrophil activation and death assays}

Levels of calprotectin (S100A8/A9) were analyzed using a commercial ELISA kit according to the manufacturer's instruction (R\&D Systems). Levels of MPO-DNA and NE-DNA complexes were analyzed using sandwich ELIS As as described before [25, 26]. Briefly, a 96-well microtiter plate was coated with capture antibody, $4 \mu \mathrm{g} / \mathrm{mL}$, followed by blocking with $1 \%$ BSA. After blocking, plasma samples, diluted $1 / 10$, were added and incubated overnight. For detection, anti-dsDNA-HRP antibody (diluted 1/100, Roche Diagnostics) was added for $2 \mathrm{~h}$. The reaction was developed with 3,3',5,5' -tetramethylbenzidine (TMB, BD Biosciences), and ended by the addition of $2 \mathrm{~N}$ sulfuric acid. Absorbance was measured at 450 nm by a plate reader (Synergy, BioTek). Pure MPODNA and NE-DNA complexes of known concentration were used as standard curve.

\section{Immune cell isolation}

Polymorphonuclear (PMN) and peripheral blood mononuclear cells (PBMC) were isolated from freshly drawn venous blood by gradient centrifugation on PolymorphPrep according to the manufacturer's instructions. Cells were washed and suspended in Hanks' buffered salt solution at $10^{7} / \mathrm{ml}$.

\section{Immunoblotting}

PMN or PBMC were lysed by mixing $10^{7}$ cells in $100 \mu \mathrm{l}$ with an equal volume of twice concentrated SDS sample buffer, heated at $95^{\circ} \mathrm{C}$, and clarified by centrifugation. In total, $50 \mu \mathrm{l}\left(2.5 \times 10^{6}\right.$ cell equivalents $)$ samples were resolved by SDS gel electrophoresis and transferred to nitrocellulose membranes, which were blocked in $1 \%$ bovine serum albumin in Tris-buffered saline. Filters were incubated with $4 \mathrm{H} 1$ anti-p40 mAb diluted 1:1000 in blocking buffer overnight, washed extensively in blocking buffer with $0.2 \%$ Tween-20, and developed with horseradish-conjugated anti-mouse antibody and enhanced chemiluminescence detection.

\section{Flow cytometry}

Cells were washed twice in phosphate-buffered saline (PBS) with $1 \%$ bovine serum albumin and $1 \%$ mouse serum and then stained with a mixture of antibodies against surface antigens: anti-CD66b (PE/Cy7-labeled, Biolegend \#305115) at 1:50, anti-CD16 (PerCP-labeled, clone 3 G8 Biolegend \#302029) at 1:200, anti-CD14 (PElabeled anti-human CD14 antibody clone 63D3 (Biolegend \#367103) at 1:200, and anti-CD19 (APC/Cyanine7conjugated, clone HIB19, Biolegend \#302218) at 1:200, anti-CD15 (PerCP-conjugated, clone W63D, Biolegend \#323018) at 1:200 in PBS with $1 \%$ BSA and $1 \%$ mouse serum for $30 \mathrm{~min}$ at $4{ }^{\circ} \mathrm{C}$ in the dark. The cells were washed twice, fixed in $1 \%$ paraformaldehyde in PBS, permeabilized in $200 \mu \mathrm{l} 0.1 \%$ Tween in PBS for $30 \mathrm{~min}$ at room temperature, washed and resuspended in $50 \mu \mathrm{l}$ the same buffer with 1:500 diluted anti-L1 p40 (clone 4H1, EMD Millipore MABC1152) conjugated to APC using Mix-n-Stain ${ }^{\mathrm{Tm}}$ Fluorescent Protein \& Tandem Dye Antibody Labeling Kits (Biotium \#92306). After $30 \mathrm{~min}$ at $4{ }^{\circ} \mathrm{C}$ in the dark, the cells were washed twice with PBS, $1 \% \mathrm{BSA}$, and $1 \%$ mouse serum and resuspended in $200 \mu \mathrm{l}$ of this buffer for analysis on a CytoFLEX Flow Cytometer (Beckman Coulter).

\section{Statistical analyses}

For non-paired sample sets with non-Gaussian distribution, Mann-Whitney U test, and Spearman's correlation test were used, as applicable. For paired sample sets, Wilcoxon matched-pair signed rank test was used. As a cutoff for positivity, the 95th percentile of the healthy controls was used. GraphPad Prism (version 8.4.3) and IBM SPSS were used for the analyses. All analyses were considered statistically significant at $p<0.05$.

\section{Results}

IgG autoantibodies against L1 p40 are elevated in pSLE, compared to healthy children, JIA, and JDM

As most adult SLE patients have IgG autoantibodies that recognize ORF1p/p40 encoded by $L 1$ that can be detected both by immunoblotting and ELISA [24], we used the latter assay to quantitate anti-p40 reactive IgG in pSLE patients. At the time of diagnosis and with active disease, the 30 pSLE patients had much higher anti-p40 reactivity than healthy controls, JIA, and JDM patients $(p<0.0001)$ (Fig. 1A). Using the 95th percentile of the healthy controls as a cutoff for a "normal" range, 26 $(87 \%)$ of the pSLE patients were above this cutoff, compared to only 2 of the healthy children. JIA patients showed a slight increase with 12 (38\%) of patients having anti-p40 titers above this cutoff, but the difference compared to healthy controls was statistically significant at $p$ $=0.0145$. Children with JDM had only slightly higher titers than those of healthy children. 

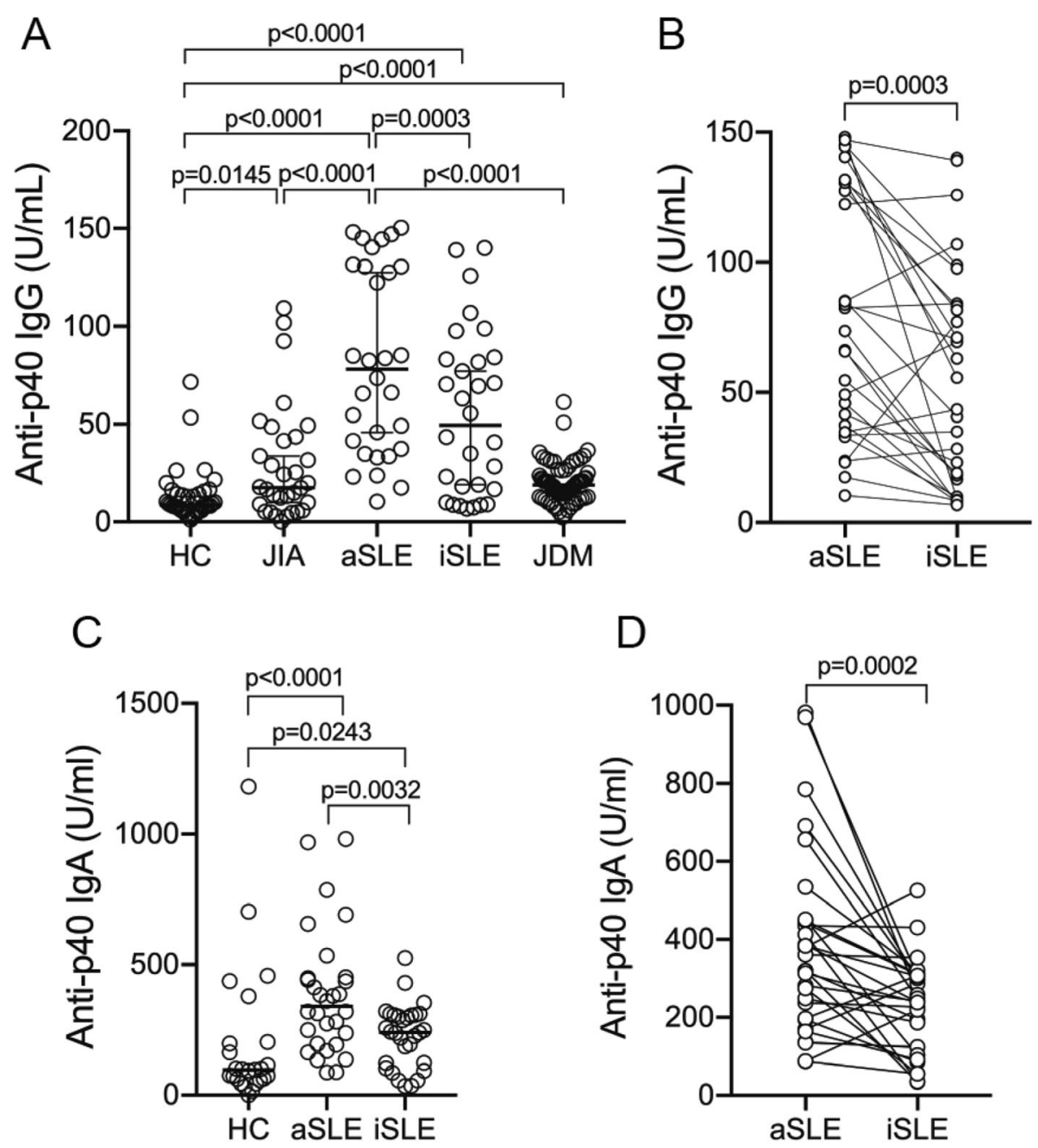

Fig. 1 Plasma from pediatric SLE patients contain lgG autoantibodies reactive with L1 p40 protein. A Quantitation by ELISA of anti-p40 IgG in the plasma of healthy control children ( $\mathrm{HC} ; n=37)$ or patients with juvenile idiopathic arthritis $(J \mathrm{~A} ; n=32)$ or pediatric SLE patients before treatment (active, aSLE; $n=30$ ) or the same patients after treatment (inactive, iSLE; $n=30$ ). B Comparison of anti-p40 lgG reactivity in each pSLE patient before and after treatment. C Quantitation of anti-p40 lgA in the plasma of HC children and pSLE patients before or after treatment. D Comparison of anti-p40 IgA reactivity in each PSLE patient before and after treatment

Anti-p40 autoantibody levels are higher in patients with active disease

Anti-p40 reactivity was significantly ( $p=0.0003$ by Wilcoxon matched-pair signed rank test) reduced in the second plasma sample from the pSLE patients taken either after several months of therapy, to which many of them had responded well and lowered their SLEDAI score to $\leq 4$ (Fig. 1A), or at a time of inactive disease before a subsequent flare. In $22(73 \%)$ of the patients, the titers were reduced, in 4 they were essentially unchanged, and in 4 they were somewhat increased (Fig. 1B). Nevertheless, 19 (63\%) of the patients still had anti-p40 titers above the 95th percentile of the healthy controls, a statistically significant difference $(p<0.0001)$ to this control group.

\section{Anti-p40 autoantibodies of IgA class are also elevated, but not IgM or IgE}

To quantitate autoantibodies of other classes than IgG, we used different Ig class-specific secondary antibodies in the ELISA and found that the pSLE patients with active disease had elevated $\operatorname{IgA}$ reactivity $(p<0.0001)$, as did the patients with inactive diseases $(p=0.0032$; Fig. 1C) compared to healthy children. In 25 patients, the titers were lower when their disease was inactive, while it was unchanged in 2 and somewhat increased in 3 (Fig. 1D). These differences were statistically significant ( $p=0.0002$ by Wilcoxon matched-pair signed rank test). In contrast, recognition of $\mathrm{p} 40$ by IgM antibodies was similar between the groups and IgE were generally very low (data not shown). 
Anti-p40 autoantibodies correlate with disease activity and complement consumption

The IgG autoantibody titers also correlated with the SLE disease activity index (SLEDAI; $r=0.65, p=0.0001$ ) (Fig. 2A), erythrocyte sedimentation rate (ESR; $r=0.43$, $p=0.02$ ) (Fig. 2B), complement $\mathrm{C} 3$ and $\mathrm{C} 4$ consumption $(r=-0.55, p=0.002$ and $r=-0.51, p=0.006$, respectively) (Fig. 2C, D), and anti-dsDNA antibodies $(r=0.49$, $p=0.03$ ) (Fig. 2E). Collectively, these data indicate that higher anti-p40 IgG levels tend to accompany active disease. Anti-p40 IgA levels correlated positively with ESR $(r=0.445, p=0.026)$, but did not correlate in a
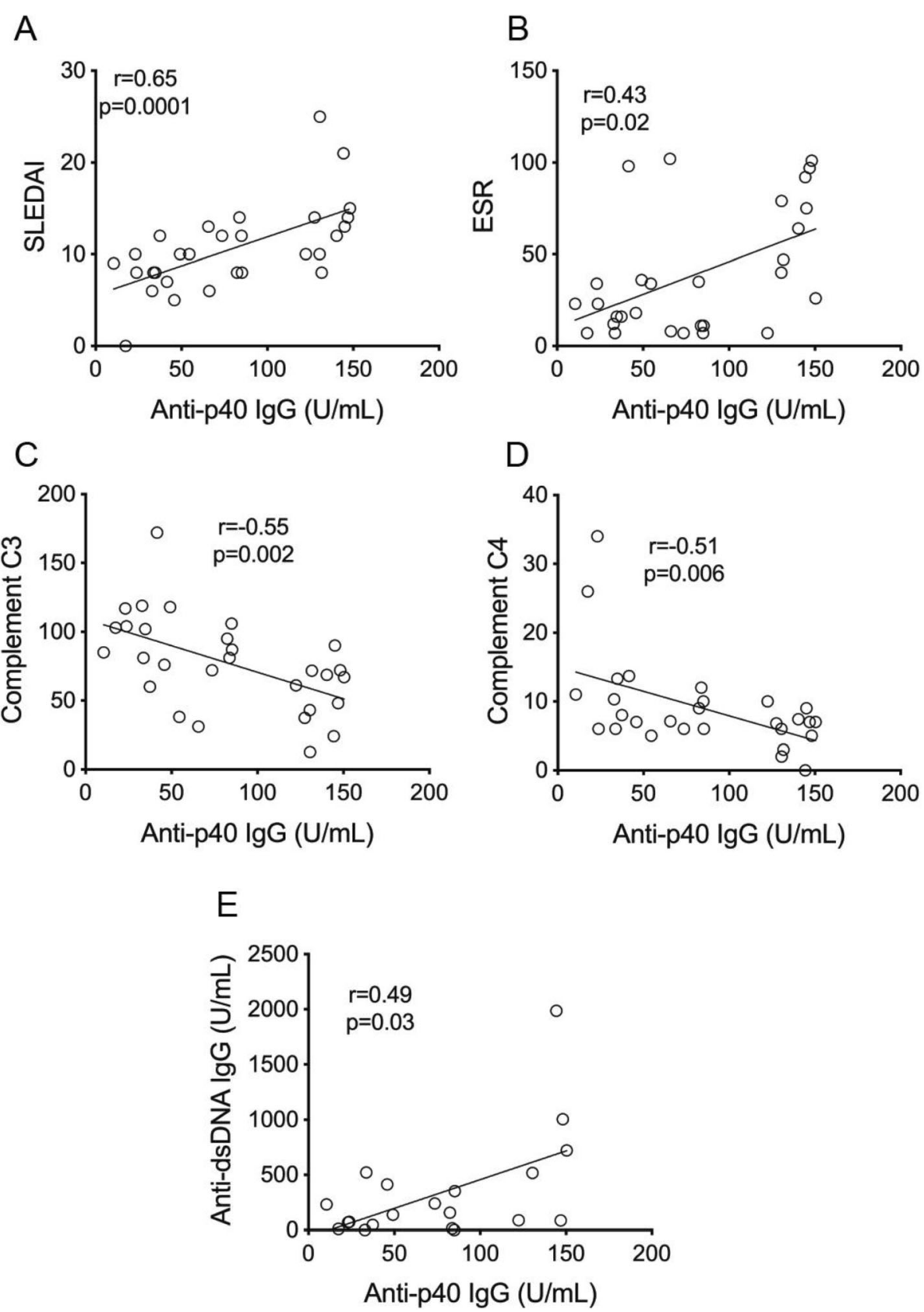

Fig. 2 Correlations of autoantibodies against L1 p40 with markers of disease activity. A Correlation between anti-p40 autoantibodies and SLEDAI in 29 of the 30 pediatric SLE patients with active disease before treatment. B Correlation with erythrocyte sedimentation rate (ESR) in 29 of the 30 pediatric SLE patients. C Inverse correlation with complement C3 levels in 29 of the 30 pediatric SLE patients. D Inverse correlation with complement C4 levels in 28 of the 30 pediatric SLE patients. E Correlation between anti-p40 autoantibodies and anti-dsDNA autoantibody levels in 20 of the 30 pediatric SLE patients with active disease before treatment. Statistical significance by Mann-Whitney $U$ test and correlation by Spearman's correlation test 
statistically significant manner with other measures of disease activity.

\section{Detection of $\mathrm{p} 40$ in patient immune cells}

We first searched for detectable p40 in leukocyte linages in the PBMC from 5 patients with pSLE and found that all of them had detectable p40 in a subset that varied from 2.4 to $44.2 \%$ (mean $16.1 \pm 17.6 \%$; standard deviation, SD) of their CD66b+ granulocytes, while much smaller fractions of their CD19+ B cells $(0-5.2 \%)$ or CD14+ monocytes (0-19\%) were positive compared to control antibody-stained cells analyzed by flow cytometry (Fig. 3A; gating strategy and representative results are shown in supplemental Fig. S1). To better explore this finding, we recruited 10 adult SLE patients and 5 healthy adult controls and analyzed their PMN and PBMC fractions by flow cytometry using more lineage markers. These experiments revealed that $\mathrm{p} 40$ was detectable in $12.2 \pm 16.6 \%$ (range $0-56 \%$ ) of CD66b + cells in the PMN fractions (Fig. 3B). These values are statistically different from those in T cells $(p=0.007)$ and $\mathrm{B}$ cells $(p=0.015)$. In the lower-density PBMC fraction, a

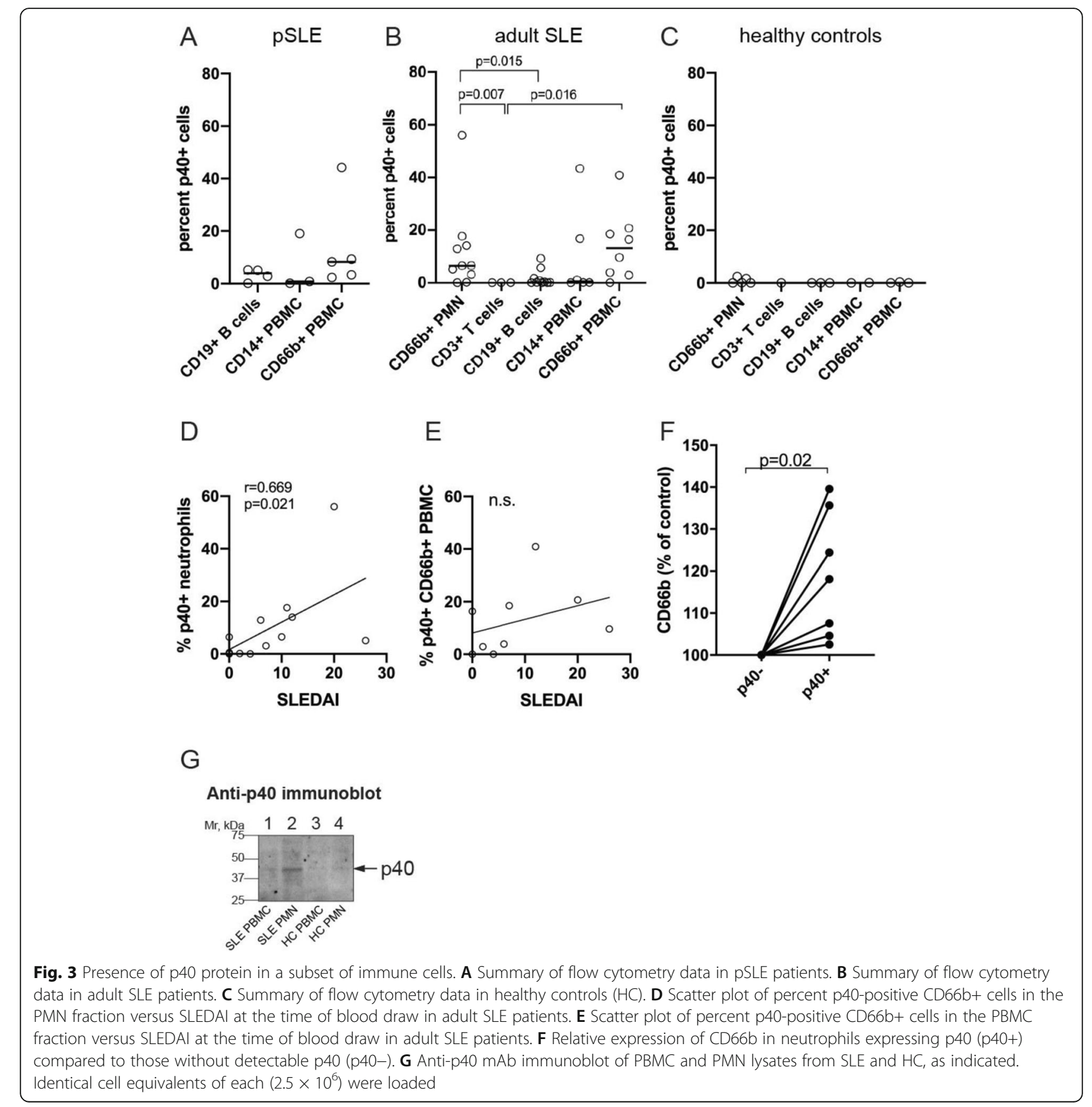


similar portion $(14.1 \pm 13.3 \%$, range $0-40.9 \%)$ of the CD66b + cells were also positive for p40 (Fig. 3B), a statistically significant difference from the $\mathrm{T}$ cells $(p=$ 0.016). Only two patients had detectable p40 in their B cells and none in their T cells, while the CD14+ cells in the PBMC fraction, which include monocytes and granulocytes, were positive in two patients (43.4\% and $16.7 \%$, respectively). In healthy controls, all leukocyte lineages were negative for $\mathrm{p} 40$ (Fig. 3C). These data indicate that neutrophils, particularly considering that they constitute approximately half of all immune cells in circulation, are the predominant cells expressing p40 protein in SLE patients, but that the number of positive cells varied broadly. Patients with the highest SLEDAI scores at the time of blood draw correlated with the highest portion of p40-positive neutrophils in the PMN $(r=0.669, p=$ 0.021) (Fig. 3D). A trend towards a similar correlation was seen between SLEDAI and the portion of $\mathrm{p} 40$ positive $\mathrm{CD} 66 \mathrm{~b}+$ cells in the PBMC fractions (Fig. 3E), but this trends did not meet statistical significance.

The median fluorescence intensity of CD66b staining of neutrophils with detectable p40 was somewhat higher $(p=0.02)$ than of neutrophils without p40 in 7 of the p40-expressing patients (Fig. 3F), suggesting that the presence of $\mathrm{p} 40$ may be associated with a more activated neutrophil phenotype. As an independent validation, immunoblotting of cell lysates showed that the PMN fraction from SLE patients had more p40 than the PBMC fraction, while healthy controls were negative (Fig. 3G).

\section{Markers of neutrophil activation and NETosis are elevated in PSLE patients}

Because p40 appears to be expressed predominantly in neutrophils in both the pediatric and adult SLE patients, and perhaps more so in activated neutrophils, we measured markers for neutrophil activation and NETosis, which have been developed in our lab [26-29]. Myeloperoxidase (MPO) and/or neutrophil elastase (NE) in complex with free DNA in plasma reflect death of neutrophils, including (and perhaps mostly) by NETosis [25]. A second marker, levels of the S100A8/A9 proteins (also known as calprotectin), which reflects neutrophil activation was also measured. As shown in Fig. 4A-C, these markers were all elevated in the plasma of the 30
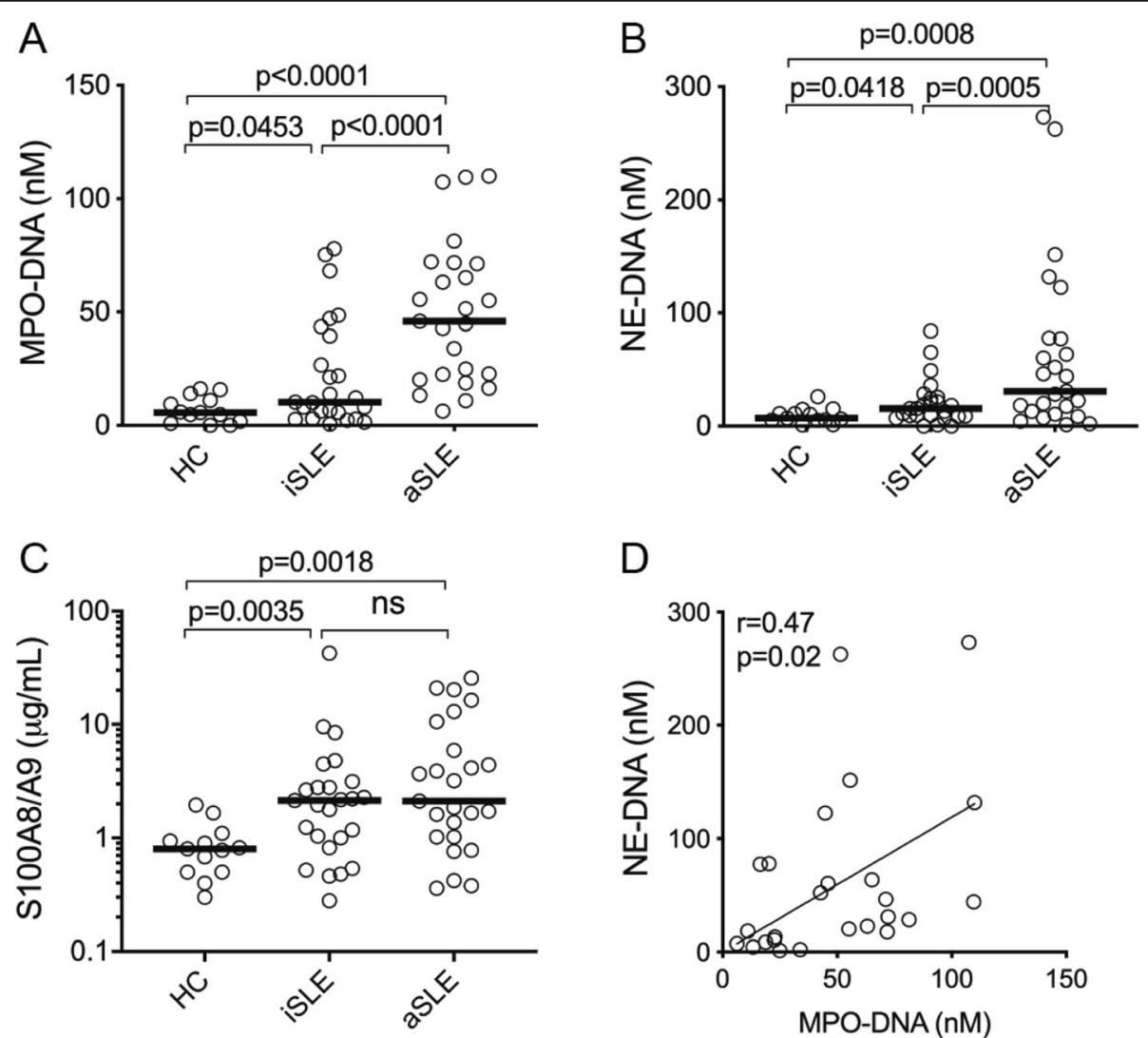

Fig. 4 Markers of neutrophil death in pSLE patients and healthy controls. A Levels of MPO-DNA complexes in healthy controls (HC) and pediatric lupus patients with inactive (iSLE) and active (aSLE) disease. B Levels of NE-DNA complexes in the same patient groups. C Levels of calprotectin (S100A8/A9) in the same patient groups. D Correlation between MPO-DNA and NE-DNA complexes in patients with active disease. Statistical significance by Mann-Whitney $U$ test and Wilcoxon, and correlation by Spearman's correlation test 
pSLE patients with active disease, as well as to a lower extent in samples taken from the patients during inactive disease. The levels of MPO-DNA and NE-DNA complexes correlated with each other both during active disease $(r=0.47, p=0.018)$ (Fig. 4D) and during inactive disease $(r=0.52, p=0.008)$ when the values were lower (not shown).

\section{Anti-p40 autoantibodies correlate with markers of neutrophil death and activation}

In pSLE patients with active disease, the titers of anti-p40 autoantibodies of IgG class correlated with MPO-DNA complexes $(r=0.412, p=0.041)$ (Fig. $5 \mathrm{~A})$ and S100A8/A9 $(r=0.489, p=0.013$ ) (Fig. 5B). However, in inactive disease, only MPO-DNA complexes, but not S100A8/A9, correlated with anti-p40 IgG autoantibodies (Fig. 5C, D).

Anti-p40 IgA autoantibodies only correlated statistically significantly with MPO-DNA complexes $(r=0.15$, $p=0.022$ ) in active SLE (Fig. 6A). In healthy controls, all neutrophil markers and autoantibodies were low and did not correlate with each other in a statistically significant manner (Fig. 5E, F; Fig. 6E, F).

\section{Discussion}

We report several novel findings in children with recentonset lupus, which may be connected with each other.
A

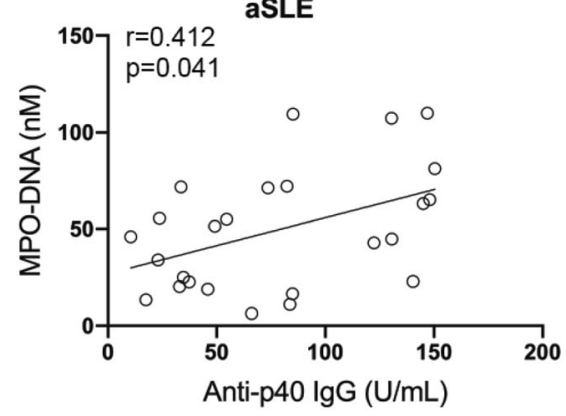

C

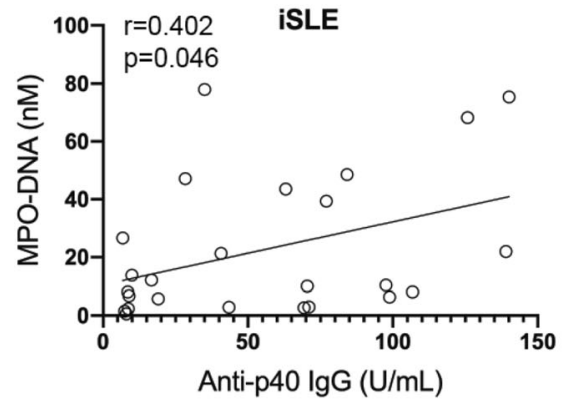

E

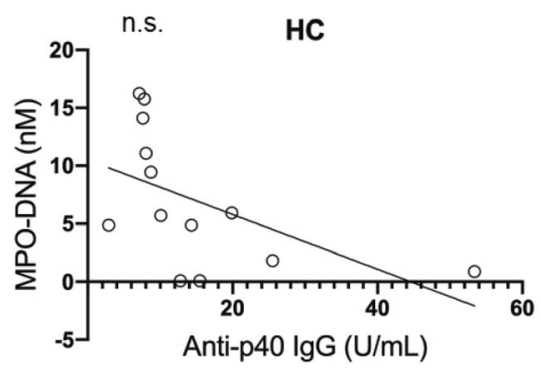

B

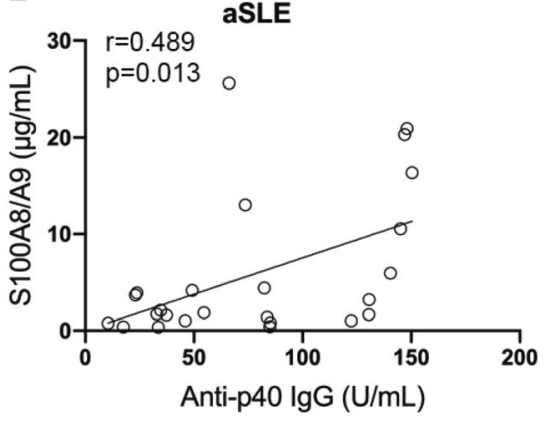

iSLE

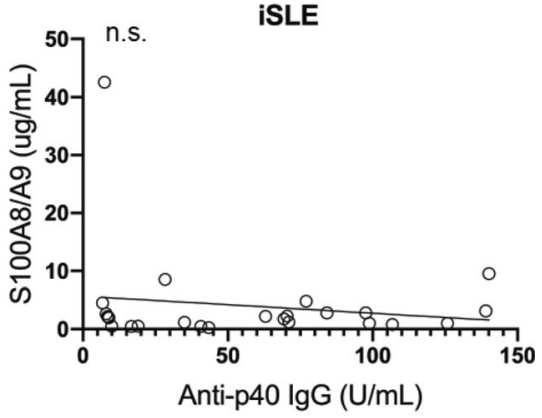

$\mathrm{F}$

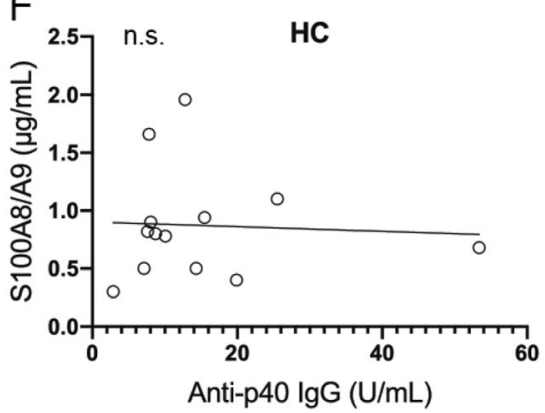

Fig. 5 Correlations between IgG anti-p40 autoantibodies and markers of neutrophil death in pSLE patients with active disease and healthy controls. A Correlation between levels of MPO-DNA complexes and anti-p40 lgG antibodies in active pSLE patients. B Correlation between levels of S100A8/A9 and anti-p40 lgG antibodies in active pSLE patients. C Correlation between levels of MPO-DNA complexes and anti-p40 lgG antibodies in inactive pSLE patients. D Lack of correlation between levels of calprotectin and anti-p40 lgG antibodies in inactive pSLE patients. $\mathbf{E}$ Lack of correlation between levels of MPO-DNA complexes and anti-p40 lgG antibodies in healthy controls. $\mathbf{F}$ Lack of correlation between levels of calprotectin and anti-p40 lgG antibodies in healthy controls. 

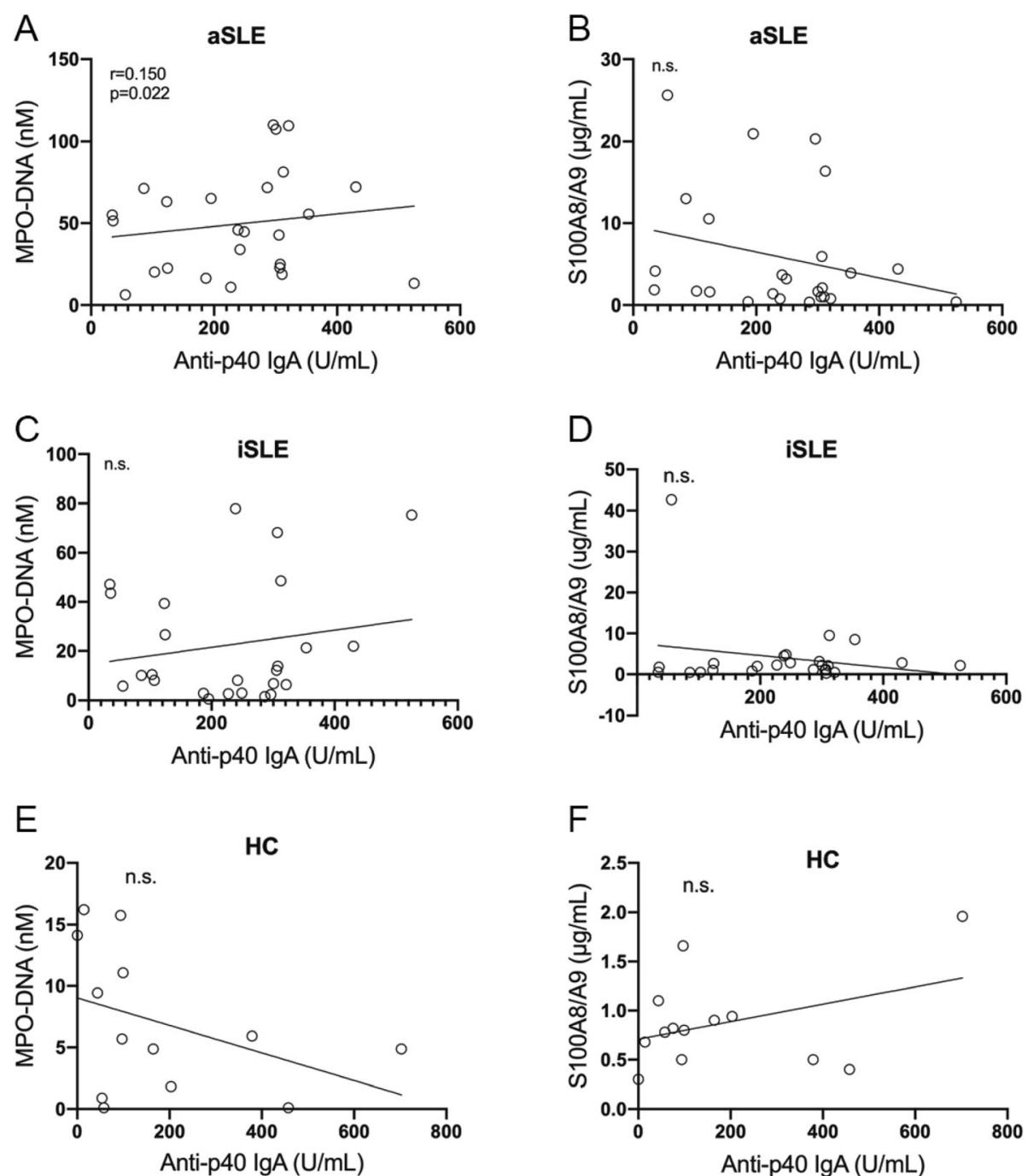

Fig. 6 Correlations between IgA anti-p40 autoantibodies and markers of neutrophil death in pSLE patients with active disease and healthy controls. A Correlation between levels of MPO-DNA complexes and anti-p40 lgA antibodies in active pSLE patients. B Lack of correlation between levels of calprotectin and anti-p40 lgA antibodies in active pSLE patients. C Lack of correlation between levels of MPO-DNA complexes and antip40 IgA antibodies in inactive pSLE patients. D Lack of correlation between levels of calprotectin and anti-p40 IgA antibodies in inactive pSLE patients. E Lack of correlation between levels of MPO-DNA complexes and anti-p40 IgA antibodies in healthy controls. $\mathbf{F}$ Lack of correlation between levels of calprotectin and anti-p40 lgA antibodies in healthy controls

First, that autoantibodies against p40/ORF1p encoded by the L1 retroelement are prevalent in pediatric patients with SLE with active and recently diagnosed disease, compared to those with inactive disease or healthy controls. In contrast, pediatric patients with JIA or JDM had considerably lower reactivity with $\mathrm{p} 40$. Similarly, while adult SLE patients also have anti-p40 autoantibodies, patients with scleroderma [24] or rheumatoid arthritis (our unpublished observation) are generally low or negative compared to healthy controls, with only a few individual exceptions. Healthy adults also tend to have somewhat higher levels of anti-p40 antibodies than healthy children. These modest levels also tend to increase with age, perhaps related to the recently documented role of L1 retroelements in cellular senescence [23]. Our finding of anti-p40 autoantibodies in SLE has also been independently confirmed [30].

Second, we find that pSLE patients with active disease also have significantly elevated IgA autoantibodies in circulation against $\mathrm{p} 40$ compared to healthy controls, while patients with clinically inactive disease have intermediate levels. In contrast, adults with active SLE do not have IgA titers that differ from those of healthy controls (our unpublished observation). These data may indicate that IgA autoantibodies are uniquely elevated in the earliest stages of lupus disease and decrease to background levels with time. Since IgAs are particularly important for immunity on mucosal surfaces, their presence in 
pSLE patients may have implications for the anatomical location(s) where lupus pathogenesis is initiated.

Third, we find that $\mathrm{p} 40$ protein is present in a subset of circulating neutrophils both in pediatric and in adult SLE patients, particularly in those with active disease. The p40-positive neutrophils were not only present in the higher-density PMN fraction, but also in the lowerdensity PBMC fraction, suggesting that these p40positive cells may include the unique subset of lowdensity granulocytes (LDGs) that have garnered considerable interest in SLE pathogenesis in recent years [31]. Of note, neutrophils are prevalent on mucosal surfaces and express more Fc $\alpha$ R than other immune cells.

Fourth, we report that markers of neutrophil death by pathways that result in circulating DNA in complex with the neutrophil-specific enzymes MPO or NE are significantly elevated in pSLE patients with active disease compared to healthy controls. Samples from the same patients when their disease was inactive showed intermediate levels. Neutrophils from pSLE patients with active disease also had markedly elevated circulating S100A8/A9, indicative of neutrophil activation.

While presently only speculation, one could envision a scenario where the activation and death of p40expressing neutrophils, some of them perhaps on mucosal surfaces, may be causally connected to increasing levels of IgG and IgA anti-p40 autoantibodies during active disease. The data in adult SLE patients are also compatible with this scenario. When complexed with released p40 (likely with bound RNA), the resulting IgG or IgA immune complexes may further activate neutrophils and induce their death by NETosis, escalating a detrimental feedback loop of potential importance in the pathogenesis of SLE. In this context, it might also be relevant that p40 exists in cells in a macromolecular assembly that includes Ro60, La-related proteins, snRNPs, and associated RNA [32-34]. Hence, p40 released from dying neutrophils may be associated with these proteins in addition to RNA.

The L1 encoded proteins ORF1p/p40 and ORF2p/ p145 may play additional roles in SLE similar to the recently recognized role of L1 in cellular senescence and the associated production of IFN $\beta$ and age-related inflammation [23]. The mechanism for this involves the ORF2p protein, which is a reverse transcriptase that generates RNA:DNA hybrids and dsDNA that trigger the DNA sensor cGAS [10]. This same mechanism drives type I IFN production in certain forms of the interferonopathy known as Aicardi-Goutières syndrome [35], in which inhibitors of the reverse transcriptase reduced the interferon gene signature in a small clinical trial [36]. The production of IFN $\beta$ by senescent cells was also inhibited by reverse transcriptase inhibitors in tissue culture and in mice [23]. Whether these events also take place in p40-expressing neutrophils in SLE patients is currently under investigation in our laboratory. More specifically, we are measuring IFN $\beta$ and IFN-induced genes in neutrophils and are testing if reverse transcriptase inhibitors will block them. We are also using RNA sequencing to determine which L1 elements are expressed in SLE neutrophils.

\section{Conclusions}

Our findings indicate that elevated L1 retrotransposon expression, primarily in neutrophils (among immune cells), is an early event in children developing pSLE, as well as in adults with a disease exacerbation. Active disease also associates with increased neutrophil activation and death, suggesting that immunogenic p40 may be released from these cells, resulting in the generation of IgG and IgA autoantibodies against p40. Limitations of our study include only two time-points of sampling, analysis of autoantibodies and neutrophils in blood only, but not bone marrow or tissue.

\section{Abbreviations}

ACPA: Anti-citrullinated protein antibodies; ANA: Antinuclear antibodies; BSA: Bovine serum albumin; CRP: C-reactive proteins; DMARD: Diseasemodifying antirheumatic drugs; ELISA: Enzyme-linked immunosorbent assay; ESR: Erythrocyte sedimentation rate; HC: Healthy controls; HRP: Horseradish peroxidase; IFN: Interferon; JDM: Juvenile dermatomyositis; JIA: Juvenile idiopathic arthritis; LDGs: Low-density granulocytes; LINE-1: L1, long interspersed nuclear element; MHC: Major histocompatibility complex; MPO: Myeloperoxidase; NE: Neutrophil elastase; NSAID: Non-steroidal antiinflammatory drugs; ORF1p: Open-reading frame 1-encoded protein; ORF2p: Open-reading frame 2-encoded protein; PBMC: Peripheral blood mononuclear cells; PBS: Phosphate-buffered saline; PMN: Polymorphonuclear cells; pSLE: Pediatric SLE; RF: Rheumatoid factor; SD: Standard deviation; SDS: Sodium dodecyl sulfate; SLE: Systemic lupus erythematosus;

TMB: 3,3',5,5'-tetramethylbenzidine

\section{Supplementary Information}

The online version contains supplementary material available at https://doi. org/10.1186/s13075-021-02538-3.

Additional file 1: Figure S1. Flow cytometry and gating strategy for two representative pSLE patients. A, first patient: gating on live cells, then single cells, then expression of CD66b or CD19, then p40 in the CD66b+ and CD19+ populations. Note that p40 is predominantly found in the CD66b+ population with higher CD66b expression, presumably activated neutrophils. B, second patient: same gating strategy, showing CD66b+ and CD16+ populations.

\section{Acknowledgements}

We thank the patients who participated in this study and Dr. Sladjana Skopelja-Gardner for valuable comments on the manuscript.

\section{Authors' contributions}

$K C U, M S T, J L, C L$, and TM contributed to the conception and study design. $\mathrm{KCU}, \mathrm{KN}, \mathrm{XW}, \mathrm{LMP}, \mathrm{ME}$, and $\mathrm{AS}$ contributed to data collection. $\mathrm{KCU}, \mathrm{KN}, \mathrm{CL}$, and $\mathrm{TM}$ analyzed the data. $\mathrm{KCU}, \mathrm{KN}, \mathrm{CL}$, and $\mathrm{TM}$ contributed to interpretation of the data. TM wrote the first version of the manuscript and $K C U, K N, X W$, $M S T, J L, L M P, M E, A S$, and $C L$ revised it critically. All authors read and approved the final manuscript. 


\section{Funding}

This work was supported by National Institutes of Health (T32 AR007108 to KCU, T32 CA009216 to MST, R21 AR075134 and R01 AR074939 to TM), Lupus Research Alliance grant 519414 (to CL), and CureJM Foundation (to LMP).

\section{Availability of data and materials}

The datasets used and/or analyzed during the current study are available from the corresponding author on reasonable request.

\section{Declarations}

\section{Ethics approval and consent to participate}

The study was approved by the Seattle Children's Research Hospital Human Subjects Committee (PIROSTUDY14045), the Institutional Review Board of the Ann \& Robert H. Lurie Children's Hospital of Chicago, Northwestern University Feinberg School of Medicine (\#2001-11715, \#2008-13457), and the University of Washington Institutional Review Board (STUDY00006196). Informed written consent was obtained from all participants or their parents or guardians according to the Declaration of Helsinki.

\section{Consent for publication}

Not applicable.

\section{Competing interests}

TM reports personal consulting fees from Kiniksa, from Cugene, from QiLu Biopharma, and from Miro Bio, all outside the scope of this paper. AS is an employee of Janssen Research \& Development. CL holds a pending patent for some of the neutrophil assays.

\section{Author details}

Division of Rheumatology, University of Washington, 750 Republican Street, Room E507, Seattle, WA 98109, USA. ²Massachusetts General Hospital, Boston, and Whitehead Institute, Cambridge, MA, USA. ${ }^{3}$ The Rockefeller University, New York, NY, USA. "European Research Institute for the Biology of Ageing, University Medical Center Groningen, Groningen, The Netherlands. ${ }^{5}$ Ann \& Robert H. Lurie Children's Hospital of Chicago, and Northwestern University Feinberg School of Medicine, Chicago, IL, USA. ${ }^{6}$ Seattle Children's Hospital, Seattle, WA 98105, USA. ${ }^{7}$ Seattle Children's Research Institute, Seattle, WA 98101, USA. ${ }^{8}$ Current affiliation: Jansen Research and Development LLC, Malvern, PA, USA.

Received: 12 October 2020 Accepted: 19 May 2021

Published online: 29 May 2021

\section{References}

1. Kolumam GA, Thomas S, Thompson LJ, Sprent J, Murali-Krishna K. Type interferons act directly on CD8 T cells to allow clonal expansion and memory formation in response to viral infection. J Exp Med. 2005;202(5): 637-50. https://doi.org/10.1084/jem.20050821.

2. Bengtsson AA, Sturfelt G, Truedsson L, Blomberg J, Alm G, Vallin $H$, et al. Activation of type I interferon system in systemic lupus erythematosus correlates with disease activity but not with antiretroviral antibodies. Lupus. 2000;9(9):664-71. https://doi.org/10.1191/096120300674499064.

3. Baechler EC, Batliwalla FM, Karypis G, Gaffney PM, Ortmann WA, Espe KJ, et al. Interferon-inducible gene expression signature in peripheral blood cells of patients with severe lupus. Proc Natl Acad Sci U S A. 2003;100(5): 2610-5. https://doi.org/10.1073/pnas.0337679100.

4. Bennett L, Palucka AK, Arce E, Cantrell V, Borvak J, Banchereau J, et al. Interferon and granulopoiesis signatures in systemic lupus erythematosus blood. J Exp Med. 2003;197(6):711-23. https://doi.org/10.1084/jem.20021553.

5. Crow MK, Kirou KA, Wohlgemuth J. Microarray analysis of interferonregulated genes in SLE. Autoimmunity. 2003;36(8):481-90. https://doi.org/1 0.1080/08916930310001625952.

6. Baechler EC, Bauer JW, Slattery CA, Ortmann WA, Espe KJ, Novitzke J, et al. An interferon signature in the peripheral blood of dermatomyositis patients is associated with disease activity. Mol Med. 2007;13(1-2):59-68. https://doi. org/10.2119/2006-00085.Baechler.

7. Bave U, Nordmark G, Lovgren T, Ronnelid J, Cajander S, Eloranta ML, et al. Activation of the type I interferon system in primary Sjogren's syndrome: a possible etiopathogenic mechanism. Arthritis Rheum. 2005;52(4):1185-95. https://doi.org/10.1002/art.20998.
8. Mustelin T, Lood C, Giltiay NV. Sources of pathogenic nucleic acids in systemic lupus erythematosus. Front Immunol. 2019;10:1028. https://doi. org/10.3389/fimmu.2019.01028.

9. Loo YM, Gale M Jr. Immune signaling by RIG--like receptors. Immunity. 2011;34(5):680-92. https://doi.org/10.1016/j.immuni.2011.05.003.

10. Keating SE, Baran M, Bowie AG. Cytosolic DNA sensors regulating type ! interferon induction. Trends Immunol. 2011;32(12):574-81. https://doi.org/1 0.1016/j.it.2011.08.004.

11. Crow YJ, Manel N. Aicardi-Goutieres syndrome and the type I interferonopathies. Nat Rev Immunol. 2015;15(7):429-40. https://doi.org/10.1 038/nri3850.

12. Elkon KB. Review: cell death, nucleic acids, and immunity: inflammation beyond the grave. Arthritis Rheumatol. 2018;70(6):805-16. https://doi.org/1 0.1002 /art.40452.

13. An J, Durcan L, Woodward JJ, Karr R, Teale T, Elkon KB. cGAMP and CGAS are expressed in a subset of patients with systemic lupus erythematosus and associate with disease activity. Arthritis Rheum. 2017:69(4):800-7. https://doi.org/10.1002/art.40002.

14. Shao WH, Shu DH, Zhen Y, Hilliard B, Priest SO, Cesaroni M, et al. Prion-like aggregation of mitochondrial antiviral signaling protein in lupus patients is associated with increased levels of type I interferon. Arthritis Rheumatol. 2016;68(11):2697-707. https://doi.org/10.1002/art.39733.

15. Lander ES, Linton LM, Birren B, Nusbaum C, Zody MC, Baldwin J, et al. Initial sequencing and analysis of the human genome. Nature. 2001;409(6822): 860-921. https://doi.org/10.1038/35057062.

16. Weiss RA, Stoye JP. Virology. Our viral inheritance. Science. 2013;340(6134) 820-1. https://doi.org/10.1126/science.1235148.

17. Esnault C, Maestre J, Heidmann T. Human LINE retrotransposons generate processed pseudogenes. Nat Genet. 2000;24(4):363-7. https://doi.org/10.103 8/74184.

18. Ostertag EM, Kazazian HH Jr. Biology of mammalian L1 retrotransposons. Annu Rev Genet. 2001;35(1):501-38. https://doi.org/10.1146/annurev.genet.3 5.102401.091032.

19. Mavragani CP, Sagalovskiy I, Guo Q, Nezos A, Kapsogeorgou EK, Lu P, et al. Expression of long interspersed nuclear element 1 retroelements and induction of type I interferon in patients with systemic autoimmune disease. Arthritis Rheumatol. 2016;68(11):2686-96. https://doi.org/10.1002/a rt 39795.

20. Mavragani CP, Nezos A, Sagalovskiy I, Seshan S, Kirou KA, Crow MK. Defective regulation of $\mathrm{L} 1$ endogenous retroelements in primary Sjogren's syndrome and systemic lupus erythematosus: Role of methylating enzymes. J Autoimmun. 2018;88:75-82. https://doi.org/10.1016/j.jaut.2017.10.004.

21. Mathias SL, Scott AF, Kazazian HH Jr, Boeke JD, Gabriel A. Reverse transcriptase encoded by a human transposable element. Science. 1991; 254(5039):1808-10. https://doi.org/10.1126/science.1722352.

22. Clements AP, Singer MF. The human LINE-1 reverse transcriptase:effect of deletions outside the common reverse transcriptase domain. Nucleic Acids Res. 1998;26(15):3528-35. https://doi.org/10.1093/nar/26.15.3528.

23. De Cecco M, Ito T, Petrashen AP, Elias AE, Skvir NJ, Criscione SW, et al. L1 drives IFN in senescent cells and promotes age-associated inflammation. Nature. 2019:566(7742):73-8. https://doi.org/10.1038/s41586-018-0784-9.

24. Carter V, LaCava J, Taylor MS, Liang SY, Mustelin C, Ukadike KC, et al. High prevalence and disease correlation of autoantibodies against p40 encoded by long interspersed nuclear elements in systemic lupus erythematosus. Arthritis Rheumatol. 2020;72(1):89-99. https://doi.org/10.1002/art.41054.

25. Lood C, Blanco LP, Purmalek MM, Carmona-Rivera C, De Ravin SS, Smith CK, et al. Neutrophil extracellular traps enriched in oxidized mitochondrial DNA are interferogenic and contribute to lupus-like disease. Nat Med. 2016;22(2): 146-53. https://doi.org/10.1038/nm.4027.

26. Bach M, Moon J, Moore R, Pan T, Nelson JL, Lood C. A neutrophil activation biomarker panel in prognosis and monitoring of patients with rheumatoid arthritis. Arthritis Rheumatol. 2020;72(1):47-56. https://doi.org/10.1002/art.41 062.

27. Aleyd E, Al M, Tuk CW, van der Laken CJ, van Egmond M. IgA complexes in plasma and synovial fluid of patients with rheumatoid arthritis induce neutrophil extracellular traps via FcalphaRI. J Immunol. 2016;197(12):4552-9. https://doi.org/10.4049/jimmunol.1502353.

28. Moore S, Juo HH, Nielsen CT, Tyden H, Bengtsson AA, Lood C. Neutrophil extracellular traps identify patients at risk of increased disease activity and cardiovascular comorbidity in systemic lupus erythematosus. J Rheumatol. 2020;47(11):1652-60. https://doi.org/10.3899/jrheum.190875. 
29. Durvuri B, Pachman LM, Morgan G, Khojah AM, Klein-Gitelman M, Curran $\mathrm{ML}$, et al. Neutrophil extracellular traps in tissue and periphery in juvenile dermatomyositis. Arthritis Rheumatol. 2020;72(2):348-58. https://doi.org/10.1 002/art.41078.

30. Crow MK. Reactivity of IgG With the p40 protein encoded by the long interspersed nuclear element 1 retroelement: comment on the article by Carter et al. Arthritis Rheumatol. 2020;72(2):374-6. https://doi.org/10.1002/a rt.41102.

31. Denny MF, Yalavarthi S, Zhao W, Thacker SG, Anderson M, Sandy AR, et al. A distinct subset of proinflammatory neutrophils isolated from patients with systemic lupus erythematosus induces vascular damage and synthesizes type I IFNs. J Immunol. 2010;184(6):3284-97. https://doi.org/10.4049/ jimmunol.0902199.

32. Taylor MS, Altukhov I, Molloy KR, Mita P, Jiang H, Adney EM, et al. Dissection of affinity captured LINE-1 macromolecular complexes. Elife. 2018;7. https:// doi.org/10.7554/eLife.30094.

33. Taylor MS, LaCava J, Dai L, Mita P, Burns KH, Rout MP, et al. Characterization of L1-ribonucleoprotein particles. Methods Mol Biol. 2016;1400:311-38. https://doi.org/10.1007/978-1-4939-3372-3_20.

34. Taylor MS, LaCava J, Mita P, Molloy KR, Huang CR, Li D, et al. Affinity proteomics reveals human host factors implicated in discrete stages of LINE-1 retrotransposition. Cell. 2013;155(5):1034-48. https://doi.org/10.1016/j. cell.2013.10.021

35. Lim YW, Sanz LA, Xu X, Hartono SR, Chedin F. Genome-wide DNA hypomethylation and RNA:DNA hybrid accumulation in Aicardi-Goutieres syndrome. Elife. 2015:4. https://doi.org/10.7554/eLife.08007.

36. Rice Gl, Meyzer C, Bouazza N, Hully M, Boddaert N, Semeraro M, et al. Reverse-transcriptase inhibitors in the Aicardi-Goutieres syndrome. N Engl J Med. 2018;379(23):2275-7. https://doi.org/10.1056/NEJMc1810983.

\section{Publisher's Note}

Springer Nature remains neutral with regard to jurisdictional claims in published maps and institutional affiliations.

Ready to submit your research? Choose BMC and benefit from:

- fast, convenient online submission

- thorough peer review by experienced researchers in your field

- rapid publication on acceptance

- support for research data, including large and complex data types

- gold Open Access which fosters wider collaboration and increased citations

- maximum visibility for your research: over $100 \mathrm{M}$ website views per year

At $\mathrm{BMC}$, research is always in progress.

Learn more biomedcentral.com/submissions 